\title{
Increased risk of cancer in the offspring of female electronics workers
}

\author{
Tzu-I. Sung a , Jung-Der Wang a,b,c , Pau-Chung Chen ${ }^{\text {a,c, } *}$ \\ ${ }^{a}$ Institute of Occupational Medicine and Industrial Hygiene, National Taiwan University College of Public Health, Taipei, Taiwan \\ ${ }^{\mathrm{b}}$ Department of Internal Medicine, and Department of Environmental and Occupational Medicine, \\ National Taiwan University Hospital, Taiwan \\ ${ }^{\mathrm{c}}$ Center for Health Risk Assessment and Policy, National Taiwan University College of Public Health, Taipei, Taiwan
}

Received 25 April 2007; received in revised form 7 August 2007; accepted 30 August 2007

Available online 4 September 2007

\begin{abstract}
There is limited evidence on the hypothesis that maternal occupational exposure near conception increases the risk of cancer in offspring. This study is to investigate whether women employed in an electronics factory increases childhood cancer among first live born singletons. We linked the databases of Birth Registration and Labor Insurance, and National Cancer Registry, which identified 40,647 female workers ever employed in this factory who gave 40,647 first live born singletons, and 47 of them developed cancers during 1979-2001. Mothers employed in this factory during their periconceptional periods ( 3 months before and after conception) were considered as exposed and compared with those not employed during the same periods. Poisson regression model was constructed to adjust for potential confounding by maternal age, education, sex, and year of birth. Based on 11 exposed cases, the rate ratio of all malignant neoplasms was increased to 2.26 [95\% confidence interval (CI), 1.12-4.54] among children whose mothers worked in this factory during periconceptional periods. The RRs were associated with 6 years or less (RR $=3.05$; $95 \% \mathrm{CI}, 1.20-7.74)$ and $7-9$ years $(\mathrm{RR}=2.49$; 95\% CI, 1.26-4.94) of education compared with 10 years or more. An increased association was also found between childhood leukemia and exposed pregnancies $(\mathrm{RR}=3.83$; 95\% CI, 1.17-12.55). Our study suggests that maternal occupation with potential exposure to organic solvents during periconception might increase risks of childhood cancers, especially for leukemia.
\end{abstract}

(C) 2007 Elsevier Inc. All rights reserved.

Keywords: Cancer; Children; Education; Electronics; Leukemia; Organic solvents

\section{Introduction}

The discovery of uncontrolled hazardous waste sites has emerged, in many countries, as an issue of major environmental and public health concern [1]. In 1994, a hazardous waste site, polluted by the dumping of solvents from a former factory, was discovered in Taoyuan, Taiwan; the factory was built in 1970, and was in operation for the manufacturing of electronic appliances up until 1992. The factory had been inspected eight times by the Taiwanese government's inspection agency, with multiple violations of the solvent regulations having been recorded [2]. The presence of tetrachloroethylene,

\footnotetext{
* Corresponding author at: Institute of Occupational Medicine and Industrial Hygiene, National Taiwan University College of Public Health, 17 Syujhou Road, Taipei 10055, Taiwan. Tel.: +88623322 8088; fax: +886223582402.

E-mail address: pchen@ntu.edu.tw (P.-C. Chen).
}

1,1-dichloroethylene, 1,1-dichloroethane, methylene chloride, trichloroethane, 1,1,2-trichloroethane, 1,2-dichloroethane and cis-1,2-dichloroethylene was subsequently detected in the soil and groundwater [3,4]. Previous qualitative studies of interviews with the workers, corroborated by inspection records, showed a short-term high exposure to chlorinated alkanes and alkenes [5]. A significantly increased risk of breast cancer was found amongst female workers within this factory prior to the introduction of strict regulations on the use of chlorinated alkanes and alkenes [6]. Although an association between childhood cancer and parental exposure to solvents was suggested $[7,8]$ and leukemia risk was found to be associated with maternal exposure to some occupational solvents [9], results from previous studies have been inconsistent [10]. Of particular importance is that maternal occupational exposures may be harmful to their offspring. Therefore we obtained maternal employment data in this electronics factory to investigate any possible link with childhood cancer among first live born children. 


\section{Materials and methods}

A retrospective design was adopted for this study, incorporating linkage between databases of employment records of a former electronics factory from the Bureau of Labor Insurance, Taiwan National Birth and Cancer Registry. This study was approved by the Ethic Review Board of National Taiwan University College of Public Health before commencement.

The raw employment data on all female workers, covered the period from 21 May 1973 to the end of 1992 when the factory was closed, were retrieved from the database of the Bureau of Labor Insurance of Taiwan through the assistance of the Institute of Occupational Safety and Health. The Labor Insurance Act, promulgated by the government in 1958, subsequently came into effect in 1960. Thereafter, all citizens of Taiwan between the ages of 15 and 60 years were required to join the labor insurance program, either through their employer or through the establishment to which they belonged.

All live born children of female workers' offspring and their birth related data were identified by linkage of female workers' identification numbers with the Taiwan Birth Registration database, which was first established as part of household registration program by the Ministry of Interior beginning in 1978. The Taiwan household registration program is designed to gather and supply demographic information, with each birth and death being ascertained by a formal certificate written and attested by a physician. The birth-related information obtained included birth date, sex, single/multiple pregnancy, gestational age, birth weight, and parental information, including their identification numbers, birth dates, educational levels, marital status, and maternal parity. As a result, the study population comprised 103,506 children born to 47,348 female employees in the period of 1978-2001. Inclusion of multiple live born children or twins or triplets per female worker may violate the assumption of independence and causing underestimation of the variance. Thus, we restricted the analysis on 40,647 first live born singletons only in this study.

All the identification numbers of these children were then linked with the National Cancer Registry database [11] during 1979-2001 to identify how many of them developed cancer. The database is a population-based registry containing information on newly diagnosed cancer patients in all hospitals in Taiwan with 50 beds or more. The codes of all malignant neoplasms according to the standard classification system were grouped to International Classification of Diseases (ICD) 9th Revision codes 140-208, and further sub-grouped into leukemia (ICD codes 204-208). The registry is financially supported by a government agency, with registration fees being paid to the reporting hospitals on the basis of each case number reported. To verify the completeness of the cancer cases, we have attempted to list all the cancer cases that were recorded in the death certification registry during the study period, and found that all those who were certified as dead were included in the National Cancer Registry.

To determine if a female worker is "periconceptionally exposed" for a pregnancy, the subject should be employed at this factory in the period of 3 months both before and after the pregnancy began (i.e., conception). The date of conception of each pregnancy was calculated as the date of pregnancy end (i.e., birth date) minuses the length of gestation and pluses 14 days. When length of gestation was not known it was estimated as 40 weeks. On the contrary, "nonexposed" for each pregnancy meant there was no employment of the mother at this factory in the above risk period.

We estimated the effect of periconceptional exposure to potential organic solvents on the risk of all malignant neoplasms by rate ratios (RRs) using Poisson regression modeling while adjusting for maternal age and educational level, sex, and year of birth, adjusted RRs and 95\% confidence intervals (CIs) were calculated by the model. Cases with leukemia were further analyzed by stratifying all predictors into binomial variables to improve the statistical efficiency. All the analyses were performed using SAS 9.1 software (SAS Institute, Cary, NC, USA).

\section{Results}

A total of 40,647 first live born singletons were recruited in this analysis, providing a total follow-up period of 639,051
Table 1

Characteristics of 40,647 first live born children by periconceptional exposure based on 1978-2001 birth registry database in Taiwan

\begin{tabular}{|c|c|c|c|}
\hline Characteristics & Exposed $(\%)^{\mathrm{a}}$ & Nonexposed $(\%)^{\mathrm{b}}$ & $p$ value $^{\mathrm{c}}$ \\
\hline Total & $8506(100.0)$ & $32141(100.0)$ & \\
\hline Sex & & & 0.36 \\
\hline Male & $4374(51.4)$ & $16708(52.0)$ & \\
\hline Female & $4132(48.6)$ & $15433(48.0)$ & \\
\hline Year of birth & & & $<0.0001$ \\
\hline After 1990 & $513(6.0)$ & $9413(29.3)$ & \\
\hline $1985-1990$ & $2367(27.8)$ & $9861(30.7)$ & \\
\hline Before 1985 & $5626(66.1)$ & $12867(40.0)$ & \\
\hline Birth weight (grams) & & & 0.39 \\
\hline$<2500$ & $376(4.4)$ & $1460(4.5)$ & \\
\hline $2500-3499$ & $5967(70.2)$ & $22298(69.4)$ & \\
\hline$\geq 3500$ & $2163(25.4)$ & $8383(26.1)$ & \\
\hline Gestation age (weeks) & & & 0.65 \\
\hline$<37$ & $249(2.9)$ & $1000(3.1)$ & \\
\hline $37-42$ & $8201(96.4)$ & $30940(96.3)$ & \\
\hline$>42$ & $56(0.7)$ & $201(0.6)$ & \\
\hline Maternal age (years) & & & $<0.0001$ \\
\hline$<20$ & $508(6.0)$ & $1697(5.3)$ & \\
\hline $20-29$ & $7095(83.4)$ & $26424(82.2)$ & \\
\hline$\geq 30$ & $903(10.6)$ & $4020(12.5)$ & \\
\hline Maternal education (years) & & & $<0.0001$ \\
\hline$\leq 6$ & $1190(14.0)$ & $3163(9.8)$ & \\
\hline $7-9$ & $2412(28.4)$ & $10233(31.8)$ & \\
\hline$\geq 10$ & $4904(57.7)$ & $18745(58.3)$ & \\
\hline
\end{tabular}

\footnotetext{
${ }^{\text {a }}$ Mothers were working at this factory in the period of 3 months both before and after the pregnancy began (conception).

${ }^{\mathrm{b}}$ Mothers did not work at the factory in the above period.

c Based on $\chi^{2}$ tests (italics).
}

person years. The characteristics of first live born children are summarized in Table 1. The children in the exposed and nonexposed pregnancies are comparable on children's sex, birth weight, and gestation age. Two thirds of the exposed children were born before 1985, which were much higher than those of the nonexposed (40\%). Mothers with exposed children had younger age at delivery and lower education level compared with those with nonexposed children.

Table 2 compares the frequencies of age of diagnosis and sites of cancers between the exposed and nonexposed. There were 30 boys and 17 girls. Among 47 cases diagnosed with cancers, 11 occurred in the exposed pregnancies and 9 out of these 11 developed until after 10 years old, while the cancer incidences in the nonexposed peaked at around 1-4 years old. Leukemia was the most common cancer among both the exposed (55\%) and nonexposed $(25 \%)$ children.

Table 3 summarizes the results from Poisson regression analyses of all malignant neoplasms. Increased risks of cancers were found among the children with 11 cases of periconceptional exposure ( $\mathrm{RR}=2.26$; 95\% CI 1.12-4.54), and those mothers with 6 years or less $(\mathrm{RR}=3.05$; 95\% CI, 1.20-7.74) and 7-9 years $(\mathrm{RR}=2.49 ; 95 \% \mathrm{CI}, 1.26-4.94)$ of education compared with those with 10 years or more. The data indicated a tendency towards an increase in cancer incidence rates, from 1979 to 2001, but without statistical significance. In addition, there was also 
Table 2

Age of diagnosis and sites of cancers among 47 children by periconceptional exposure

\begin{tabular}{lll}
\hline Cancer sites (ICD-9) $^{\mathrm{a}}$ & Exposed $^{\mathrm{b}}$ & Nonexposed $^{\mathrm{c}}$ \\
\hline Total & 11 & 36 \\
Age of diagnosis of cancer (years) & & \\
$\quad<1$ & 0 & 1 \\
$1-4$ & 1 & 10 \\
$5-9$ & 1 & 6 \\
$10-14$ & 4 & 7 \\
$\geq 15$ & 5 & 12 \\
Cancer site & & \\
Buccal cavity and pharynx (140-149) & 0 & 3 \\
Liver (155) & 1 & 1 \\
Bone (170) & 2 & 1 \\
Connective and soft tissue (171) & 0 & 3 \\
Skin (173) & 1 & 1 \\
Breast (174) & 0 & 2 \\
Ovary (183) & 0 & 2 \\
Testis (186) & 1 & 1 \\
Brain and other nervous system (191-192) & 0 & 5 \\
Multiple myeloma (202) & 0 & 4 \\
Leukemia (204-208) & 6 & 9 \\
Others (rectum, 154; pancreas, 157; & 0 & 4 \\
$\quad$ mesothelioma, 158; mediastinum, 164) &
\end{tabular}

${ }^{a}$ Based on International Classification of Diseases, 9th Revision.

${ }^{b}$ Mothers were working at this factory in the period of 3 months both before and after the pregnancy began (conception).

${ }^{\mathrm{c}}$ Mothers did not work at the factory in the above period.

a statistically significant increase in the incidence of leukemia among exposed pregnancies $(\mathrm{RR}=3.83$; 95\% $\mathrm{CI}, 1.17-12.55)$, as shown in Table 4 . When restricted to the births before the end of 1992, there was even a higher risk $(\mathrm{RR}=4.28 ; 95 \% \mathrm{CI}$ $0.85-21.46$ ) although without statistically significance.

Table 3

Adjusted rate ratios (RRs) and 95\% confidence intervals (CIs) for all malignant neoplasms among first live born children

\begin{tabular}{|c|c|c|c|c|}
\hline Variable & Person years & No. of cases & $\mathrm{RR}^{\mathrm{a}}$ & $95 \% \mathrm{CI}$ \\
\hline \multicolumn{5}{|c|}{ Periconceptional exposure } \\
\hline Exposed & 155121 & 11 & 2.26 & \multirow[t]{2}{*}{$(1.12,4.54)$} \\
\hline Nonexposed & 483930 & 36 & 1 & \\
\hline \multicolumn{5}{|l|}{ Sex } \\
\hline Male & 331266 & 30 & 1.79 & \multirow[t]{2}{*}{$(0.95,3.35)$} \\
\hline Female & 307785 & 17 & 1 & \\
\hline \multicolumn{5}{|l|}{ Year of birth } \\
\hline After 1990 & 88347 & 9 & 1.92 & \multirow{3}{*}{$\begin{array}{l}(0.74,4.96) \\
(0.56,3.00)\end{array}$} \\
\hline 1985-1990 & 178112 & 8 & 1.30 & \\
\hline Before 1985 & 372592 & 30 & 1 & \\
\hline \multicolumn{5}{|c|}{ Maternal age (years) } \\
\hline$<20$ & 43011 & 5 & 2.16 & \multirow{3}{*}{$\begin{array}{l}(0.77,6.09) \\
(0.55,9.70)\end{array}$} \\
\hline$\geq 30$ & 54330 & 3 & 2.32 & \\
\hline $20-29$ & 541710 & 39 & 1 & \\
\hline \multicolumn{5}{|c|}{ Maternal education (years) } \\
\hline$\leq 6$ & 81339 & 7 & 3.05 & \multirow{3}{*}{$\begin{array}{l}(1.20,7.74) \\
(1.26,4.94)\end{array}$} \\
\hline 7-9 & 199905 & 21 & 2.49 & \\
\hline$\geq 10$ & 357807 & 19 & 1 & \\
\hline
\end{tabular}

\footnotetext{
${ }^{a}$ Based on Poisson regression models.
}

Table 4

Adjusted rate ratios (RRs) and 95\% confidence intervals (CIs) for leukemia among first live born children

\begin{tabular}{|c|c|c|c|c|}
\hline Variable & Person years & No. of cases & $\mathrm{RR}^{\mathrm{a}}$ & $95 \% \mathrm{CI}$ \\
\hline \multicolumn{5}{|c|}{ Periconceptional exposure } \\
\hline Exposed & 155121 & 6 & 3.83 & \multirow[t]{2}{*}{$(1.17,12.55)$} \\
\hline Nonexposed & 483930 & 9 & 1 & \\
\hline \multicolumn{5}{|l|}{ Sex } \\
\hline Male & 331266 & 9 & 0.66 & \multirow[t]{2}{*}{$(0.21,2.11)$} \\
\hline Female & 307785 & 6 & 1 & \\
\hline \multicolumn{5}{|l|}{ Year of birth } \\
\hline 1985 and after & 266459 & 9 & 2.82 & \multirow[t]{2}{*}{$(0.76,10.42)$} \\
\hline Before 1985 & 372592 & 6 & 1 & \\
\hline \multicolumn{5}{|c|}{ Maternal age (years) } \\
\hline$\geq 30$ & 54330 & 2 & 3.32 & \multirow[t]{2}{*}{$(0.62,17.81)$} \\
\hline$<30$ & 584721 & 13 & 1 & \\
\hline \multicolumn{5}{|c|}{ Maternal education (years) } \\
\hline$<10$ & 281244 & 8 & 1.93 & \multirow[t]{2}{*}{$(0.66,5.64)$} \\
\hline$\geq 10$ & 357807 & 7 & 1 & \\
\hline
\end{tabular}

${ }^{\text {a }}$ Based on Poisson regression models.

\section{Discussion}

The results of this study indicated that maternal occupation with potential exposure to organic solvents around conception might be associated with an increased risk of cancer in the offspring, especially for leukemia. And the risks of all childhood malignant neoplasms increased among mothers with lower educational levels, i.e., 9 years or less of education, which might correspond to female workers with assembly jobs with a higher likelihood of exposure to organic solvents. However, potential confounding from other risk factors must first be addressed before making further inference.

The increased risk of infant leukemia was reported to be associated with first parity [12], increased maternal age [13], higher socioeconomic status [14], maternal alcohol consumption during pregnancy [13], Down's syndrome [15], and infections in the first year of life [16]. As this study is restricted to only first live born children and age at delivery is controlled in the regression model, parity and maternal age cannot be the potential confounders. Since our finding of increased risk occurred in lower socioeconomic workers with less than 10 years of education, there might be only an underestimation of the association, if potential confounding ever existed.

The alcohol consumption rates of adult women were low or less than $15 \%$ before 1990 , and slightly increased to less than $20 \%$ according to the regular survey data undertaken by Taiwan Tobacco and Wine Monopoly Bureau [17]. Moreover, adolescent primigravida (aged less than 20) were found to be about 4-5 times more likely to drink alcohol than adult primigravida (aged over 20) in Taiwan [18]. Because the average delivery ages for the exposed and nonexposed pregnancies were almost same or $24.8 \pm 3.8$ and $25.1 \pm 3.9$ years old, respectively; and both were from the same factory and of a similar culture background. Thus, the increased risk of leukemia for the exposed periconception seemed unlikely to be explained by different alcohol consumption. 
The average age of children with Down's syndrome at the time of leukemia was 5.8 years, and $72 \%$ of them were less than 6 years old at diagnosis [19]. This study found that the average ages at the diagnosis of leukemia in exposed children were older than that of nonexposed $(11.7 \pm 6.5$ years versus $7.3 \pm 6.2$ years). Only one of six exposed cases was less than 6 years old at diagnosis, it seems that Down's syndrome is also unlikely to confound our study. Similarly, infections in the first year of life, which were associated with acute lymphoblastic leukemia and usually peaked during age of 2-5 years old [16], did not seem to confound our study, either. As the rate ratio for leukemia was 3.83 (95\% CI, 1.17-12.55), indicating a moderate strength of association, we tentatively concluded that these known risk factors were not explanatory of our findings, which lead to our suspicion on solvents exposure for their mothers.

The use of internal control for comparison in this study aims to reduce the potential confounding from other risk factors, such as food or drinking water inside the factory. This could also ensure good comparability in the collection of information in both exposed and nonexposed groups; thus, any selection bias was minimal, or indeed negligible. However, there was a similar standardized incidence ratio (SIR, 1.00; 95\% CI, 0.56-1.64) for overall leukemia but still a slightly elevated SIR (1.68; $95 \%$ CI, 0.62-3.67) for exposed children when compared with the general population in Taiwan.

In utero exposures to environmental or occupational agents have been thought to be associated with childhood leukemia [20,21]. In particular, Lightfoot suggested maternal preconceptional exposures may also result in retaining embryotoxic doses into the early stages of pregnancy [20]. If this etiological factor caused genetic effect, chromosomal abnormalities would initiate DNA damage in utero and relate to childhood leukemia postnatally [20,21]. In our previous study [6], we found an increased risk of breast cancer among these electronics female workers. This study also showed that maternal employment in this factory was associated with an increased risk of leukemia among the exposed children compared with that of the nonexposed children. After stratification by different types of leukemia, we found that acute lymphoblastic leukemia was the major morphological type in both exposed (three out of six cases) and nonexposed children (seven out of nine cases). While two cases of acute myeloblastic leukemia occurred in the exposed children, there was no such case in the nonexposed. Instead, there were two cases of chronic myeloid leukemia in the nonexposed children. Thus, our results seemed to support that in utero or preconceptional exposures to agents may play an important role for the initiation of acute leukemia in childhood.

The carcinogenic effects of various organic solvents in humans have not been consistently documented [22-24], but there were reports on the association between maternal occupational exposures to solvents during pregnancy and leukemia [25,26], and other cancers at times of conception [27]. But most studies lack of solid data on exposures and/or air concentrations. Unfortunately, our study suffered from the same limitation. Although we attempted to reconstruct such exposures, the available information was too crude and limited to permit any possible linkage to individual workers. The exposure data were largely based on a qualitative study and analysis of increased maternal risk of breast cancer [6], briefly summarized as follows: trichloroethylene was used very extensively for degreasing and cleaning in the early 1970s [28], which was replaced by tetrachloroethylene after 1974-1975. Isopropyl alcohol, acetone, methyl ethyl ketone, cleaner, cobehn spray (trichloromethane), methylene chloride, toluene, $n$-hexane, 1,2,-dichloroethane, 1,2,-dichloroethylene, and 1,1,1-trichloroethane were also used in this factory [2,5,28]. Moreover, six out of eight serial labor inspection reports also indicated inadequate wind speed and/or capture velocity of the factory's ventilation devices $[2,5,28]$, which implied that assembly workers in this factory were exposed to several organic solvents under concentrations exceeding the concurrently regulatory levels. Nonetheless, our study should be interpreted carefully because of potential ecological fallacy.

For lack of data on specific chemical exposures, we used job titles as the surrogates for exposure categorization. In general, female workers with elementary education were recruited into this factory beginning as an operator [29], assembling television sets and components and welding integrated circuits. As they became more skillful, they were promoted to testers and/or examiners. After more training, they could become a small group leader for improving production efficiency. With more experience and training, they could be promoted as a line clerk and/or foreman, who were responsible for management of disposition of chemical materials and transportation of finished parts or components for a specific production line. Workers with the above job titles were actually working at the production line and probably exposed to multiple organic solvents. On the other hand, workers with higher education were usually recruited as chiefs and managers, who generally worked in offices and were considered to have minimal or no exposure. In fact, there was no case of cancer or leukemia among children $(n=193)$ born of these managers, even if they were under exposed periods. After exclusion of 3604 person years contributed by these managers, there were slightly elevated risks for overall cancer (RR, 2.32; 95\% CI, 1.15-4.66) and leukemia (RR, 3.92; 95\% CI, $1.20-12.86)$ in exposed children.

It can be concluded that these results corroborate with an association between childhood cancer, especially leukemia and mothers employed in electronics factory with potential periconceptional exposure to organic solvents. However, the small numbers of cases and the limited information on exposures need to be considered.

\section{Acknowledgements}

We are greatly indebted to both the Labor Insurance Bureau and the Institute of Occupational Safety and Health at the Council of Labor Affairs, Executive Yuan of Taiwan, for supplying the computer data files and for providing assistance on exposure classification.

This study is supported by a special grant from the Bureau of Health Promotion, Department of Health and partly from National Health Research Institutes (NHRI-EX95-9204PP), Taiwan. 


\section{References}

[1] Lee LJ, Chung CW, Ma YC, Wang GS, Chen PC, Hwang YH, et al. Increased mortality odds ratio of male liver cancer in a community contaminated by chlorinated hydrocarbons in groundwater. Occup Environ Med 2003;60:364-9.

[2] Taiwan Provincial Government. Records of Labor Inspections. Inspection Committees of Industry and Mining, and Northern Region Inspection Office, Labor Department, Taiwan Provincial Government; 1975-1991.

[3] Bechtel Environmental, Inc. 1990 Preliminary Site Investigation Report, Taoyuan Site. Taoyuan, Taiwan. San Francisco, CA: Bechtel Environmental, Inc.; 1995.

[4] Target Environmental Services, Inc. Soil gas/perched groundwater/soil survey, Taoyuan site. Taoyuan, Taiwan/Columbia, MD: Target Environmental Services, Inc.; 1995.

[5] Bureau of Health Promotion. Literature evaluation and policy analysis of health care for RCA employees. Taichung, Taiwan: Bureau of Health Promotion, Department of Health; 2003.

[6] Sung TI, Chen PC, Lee LJH, Lin PY, Wang JD. Increased standardized incidence ratio of breast cancer in female electronics workers. BMC Public Health 2007;7:102.

[7] Colt JS, Blair A. Parental occupational exposures and risk of childhood cancer. Environ Health Perspect 1998;106(Suppl. 3):909-25.

[8] Savitz DA, Chen JH. Parental occupation and childhood cancer: review of epidemiologic studies. Environ Health Perspect 1990;88:325-37.

[9] Infante-Rivard C, Siemiatycki J, Lakhani R, Nadon L. Maternal exposure to occupational solvents and childhood leukemia. Environ Health Perspect 2005;113:787-92.

[10] Belson M, Kingsley B, Holmes A. Risk factors for acute leukemia in children: a review. Environ Health Perspect 2007;115:138-45.

[11] Yang HI, Lu SN, Liaw YF, You SL, Sun CA, Wang LY, et al. Hepatitis B e antigen and the risk of hepatocellular carcinoma. N Engl J Med 2002;347:168-74.

[12] Dockerty JD, Draper G, Vincent T, Rowan SD, Bunch KJ. Case-control study of parental age, parity and socioeconomic level in relation to childhood cancers. Int J Epidemiol 2001;30:1428-37.

[13] Shu XO, Ross JA, Pendergrass TW, Reaman GH, Lampkin B, Robison LL. Parental alcohol consumption, cigarette smoking, and risk of infant leukemia: a Children's Cancer Group study. J Natl Cancer Inst 1996;88:24-31.

[14] Hrusak O, Trka J, Zuna J, Polouckova A, Kalina T, Stary J. Acute lymphoblastic leukemia incidence during socioeconomic transition: selective increase in children from 1 to 4 years. Leukemia 2002;16:720-5.

[15] Alderton LE, Spector LG, Blair CK, Roesler M, Olshan AF, Robison LL, et al. Child and maternal household chemical exposure and the risk of acute leukemia in children with Down's syndrome: a report from the Children's Oncology Group. Am J Epidemiol 2006;164:212-21.

[16] Roman E, Simpson J, Ansell P, Kinsey S, Mitchell CD, McKinney PA, et al. Childhood acute lymphoblastic leukemia and infections in the first year of life: a report from the United Kingdom Childhood Cancer Study. Am J Epidemiol 2007;165:496- 504.

[17] Taiwan Tobacco and Wine Monopoly Bureau Taiwan-FuKien Tobacco and Wine Market Survey. Taipei, Taiwan: Taiwan Tobacco and Wine Monopoly Bureau, Taiwan Provincial Government; 1972-1996.

[18] Wang CS, Chou P. Risk factors for adolescent primigravida in Kaohsiung county, Taiwan. Am J Prev Med 1999;17:43-7.

[19] Robison LL, Nesbit Jr ME, Sather HN, Level C, Shahidi N, Kennedy A, et al. Down syndrome and acute leukemia in children: a 10-year retrospective survey from Childrens Cancer Stdy Grup. J Pediatr 1984;105:235-42.

[20] Lightfoot T. Aetiology of childhood leukemia. Bioelectromagnetics 2005; (Suppl. 7):S5-11.

[21] Greaves M. In utero origins of childhood leukaemia. Early Hum Dev 2005;81:123-9.

[22] McNally RJ, Parker L. Environmental factors and childhood acute leukemias and lymphomas. Leuk Lymphoma 2006;47:583-98.

[23] IARC. Some organic solvents, resin monomers and related compounds, pigments and occupational exposures in paint manufacture and painting (IARC monographs on the evaluation of carcinogenic risks to humans, vol 47). Lyon, France: International Agency for Research on Cancer (IARC), World Health Organization; 1989.

[24] IARC. Dry cleaning, some chlorinated solvents and other industrial chemicals. (IARC monographs on the evaluation of carcinogenic risks to humans, vol 63). Lyon, France: International Agency for Research on Cancer (IARC), World Health Organization; 1995.

[25] Shu XO, Stewart P, Wen WQ, Han D, Potter JD, Buckley JD, et al. Parental occupational exposure to hydrocarbons and risk of acute lymphocytic leukemia in offspring. Cancer Epidemiol Biomarkers Prev 1999;8: 783-91.

[26] van Steensel-Moll HA, Valkenburg HA, van Zanen GE. Childhood leukemia and parental occupation. A register-based case-control study. Am J Epidemiol 1985;121:216-24.

[27] Olsen JH, de Nully Brown P, Schulgen G, Jensen OM. Parental employment at time of conception and risk of cancer in offspring. Eur J Cancer 1991;27:958-65.

[28] RCA. RCA family. A magazine for Radio Corporation of America Taiwan employees. Taoyuan, Taiwan: Radio Corporation of America (RCA); 1973.

[29] RCA. RCA family. A magazine for Radio Corporation of America Taiwan employees. Taoyuan, Taiwan: Radio Corporation of America (RCA); 1977. 